Case Reports
in Dermatology
Case Rep Dermatol 2020;12:155-158

DOI: 10.1159/000509176

Published online: August 18, 2020 (c) 2020 The Author(s)

Published by S. Karger AG, Basel www.karger.com/cde

This article is licensed under the Creative Commons Attribution-NonCommercial 4.0 International License (CC BY-NC) (http://www.karger.com/Services/OpenAccessLicense). Usage and distribution for commercial purposes requires written permission.

\title{
A Case of Ofuji Disease Successfully Treated with the Combination of Low-Dose Indomethacin and Topical Tacrolimus
}

\author{
Claudio Marasca Angelo Ruggiero Gabriella Fabbrocini \\ Matteo Megna \\ Section of Dermatology, Department of Clinical Medicine and Surgery, University of \\ Naples Federico II, Naples, Italy
}

\section{Keywords}

Ofuji disease · Eosinophilic pustular folliculitis $\cdot$ Indomethacin $\cdot$ Tacrolimus

\begin{abstract}
Eosinophilic pustular folliculitis (EPF) (Ofuji disease) is a chronic, noninfectious pruritic cutaneous disorder of unknown etiology. No official guidelines are available for its treatment. Herein we present the case of a 59-year-old Caucasian man admitted to our outpatient clinic due to a generalized itchy skin rash characterized by papulo-pustules involving the face, trunk, and limbs. Histological examination supported the clinical diagnosis of EPF (Ofuji disease). The combination of low-dose oral indomethacin and topical tacrolimus ointment once a day led to a complete resolution of the lesions as well as associated symptoms in 8 weeks.
\end{abstract}

(C) 2020 The Author(s)

Published by S. Karger AG, Basel

\section{Introduction}

Eosinophilic pustular folliculitis (EPF) is a chronic, noninfectious pruritic cutaneous disorder of unknown etiology. It was originally described by Ise and Ofuji [1] in 1965 as a variant of "superficial pustular dermatosis" in a Japanese female patient with recurrent follicular 


\section{Case Reports in Dermatology}

Case Rep Dermatol 2020;12:155-158

DOI: $10.1159 / 000509176$

Marasca et al.: Ofuji Disease Treatment

pustules on the trunk and the face accompanied by peripheral eosinophilia. The eruption of EPF consists of papulo-pustules which tend to form annular plaques. Histologically, EPF is characterized by an eosinophil-dominated infiltrate within and around the pilosebaceous units, often accompanied by eosinophilic microabscess formation $[2,3]$. This type of EPF is currently called Ofuji disease or classic EPF. Herein, we describe the case of an immunocompetent male patient with the classic form of EPF who was successfully treated with low-dose oral indomethacin combined with topical tacrolimus.

\section{Case Report}

A 59-year-old Caucasian man was admitted at our outpatient Clinic in December 2019 presenting a severe and generalized skin rash characterized by papulo-pustules involving the face, trunk, and limbs. These manifestations were strongly itchy and not responsive to topical steroids and systemic antihistamine drugs, showing a high impact on quality of life. His medical history was positive for hypertension, arthrosis, anxiety, and depression; he also presented a percutaneous nephrostomy for a previous obstructive uropathy (2018) and a percutaneous ileostomy for a previous intestinal obstruction (2017). The patient said that the skin rash began 2 months ago, involving the face and subsequently expanding to the trunk and upper limbs. Dermatologic examination showed follicular papules and pustules, coalescing to form plaques on the face, trunk, and limbs (Fig. 1a). Routine blood tests were within normal ranges except for peripheral eosinophilia which represented $24.3 \%$ of the leukocyte formula, with a $1.91 \times 10^{3} / \mu \mathrm{L}$ count of eosinophils (normal value: $0-6 \% ; 0.0-0.45 \times 10^{3} / \mu \mathrm{L}$ ). An HIV screening was performed with negative results. A 3-mm skin biopsy was sent for histology showing skin with a rich representation of the pilosebaceous appendages, site of severe lympho-granulocytic infiltrate, with an impressive amount of eosinophilic granulocytes, which involved the annexes both superficially and deeply supporting the diagnosis of EPF (Ofuji disease). As shown by the therapeutic algorithm for EPF proposed by Takashi Nomura et al. [4], we started oral indomethacin (50 mg). Despite an initial improvement, the patient discontinued the therapy after only 1 week due to gastrointestinal events (diarrhea), manifesting an aggravation of the facial manifestations, with the appearance of new papulo-pustules. We decided to reduce the dosage of oral indomethacin from 50 to $25 \mathrm{mg}$ combining it with topical tacrolimus ointment once a day, observing the spontaneous disappearance of the gastrointestinal symptoms and an excellent response especially on the itch symptom. During the last follow-up (week 8), the patient showed a total absence of itching and an important reduction of facial manifestations (Fig. 1b).

\section{Discussion and Conclusion}

EPF is a chronic, noninfectious pruritic cutaneous disorder of unknown etiology. The eruption of EPF consists of papulo-pustules which tend to form annular plaques. Histologically, EPF is characterized by an eosinophil-dominated infiltrate within and around the pilosebaceous units, often accompanied by eosinophilic microabscess formation [1-3]. Apart from the classic EPF (Ofuji disease), which affects otherwise healthy individuals, additional variants of this disorder have been recognized: immunosuppression-associated EPF (IS-EPF) and infancy-associated EPF (I-EPF) are variants of EPF, both of which have been constantly reported since the 1980s [5]. There is also a rare drug-induced variant, which is associated with the 


\section{Case Reports in Dermatology}

administration of medications such as carbamazepine, minocycline, indeloxazine hydrochloride, and allopurinol [6-8]. The clinical features of the present case were compatible with the classic form of EPF. The diagnosis of EPF is occasionally difficult and problematic as EPF may share clinical and/or histological appearance overlapping with other diseases [5]. Because of the non-specific clinical features, histology is mandatory for the final diagnosis. Follicles must be included and studied carefully through serial sectioning. The presence of microabscesses containing eosinophil-dominant granulocytes in the upper portion of the outer root sheath is the hallmark of EPF [9]. The etiopathogenesis of EPF still remains unknown. It has been suggested that EPF most likely represents a multifactorial immunological reaction pattern to antigenic stimuli of diverse origin, which may cause an alteration of the immunological balance in the microenvironment of sebocytes leading to the production of prostaglandin $\mathrm{D}_{2}$ [4]. Many treatments have been used for classic EPF therapy (topical and systemic steroids, topical tacrolimus, systemic dapsone, sulfonamides, macrolides, tetracyclines, cyclosporine, retinoids, and systemic and topical antifungals) with variable results [4]. To our knowledge, only 1 case has been reported so far describing the efficacy of a low dose of systemic indomethacin in combination with topical tacrolimus ointment for the classic EPF [10]. To our experience, this combination could be an effectiveness and safe therapy for the Ofuji disease, reducing the dosage of oral indomethacin and its gastrointestinal adverse events. To date, no official guidelines are available for the treatment of the Ofuji disease. According to our experience, we can confirm the use of low dose of oral indomethacin $(25 \mathrm{mg})$ in combination with topical tacrolimus once a day as a first-line safe and very promising option for patients with classic EPF.

\section{Statement of Ethics}

Informed consent for the study and for the publication of the photos was obtained from the patient. The study complied with the Declaration of Helsinki. Internal board review number was not required since we present a case report that does not need to be approved by the local ethics committee; it is not an experimental or an observational study.

\section{Conflict of Interest Statement}

The authors declare no conflict of interest.

\section{Funding Sources}

None of the authors received any financial support for the present study.

\section{Author Contributions}

All named authors meet the International Committee of Medical Journal Editors (ICMJE) criteria for authorship of the manuscript, take responsibility for the integrity of the work as a whole, and gave final approval of the version to be published. 


\section{Case Reports in Dermatology}

\begin{tabular}{l|l}
\hline Case Rep Dermatol 2020;12:155-158 \\
\hline DOI: 10.1159/000509176 & $\begin{array}{l}\text { ( ) 2020 The Author(s). Published by S. Karger AG, Basel } \\
\text { www.karger.com/cde }\end{array}$ \\
\hline
\end{tabular}

Marasca et al.: Ofuji Disease Treatment

\section{References}

1 Ise S, Ofuji S. Subcorneal pustular dermatosis; a follicular variant? Arch Dermatol. 1965;92(2):169-71.

2 Ofuji S, Ogino A, Horio T, Oseko T, Uehara M. Eosinophilic pustular folliculitis. Acta Derm Venereol. 1970;50(3):195-203.

3 Ofuji S. Eosinophilic pustular folliculitis. Dermatologica. 1987;174(2):53-6.

4 Nomura T, Katoh M, Yamamoto Y, Miyachi Y, Kabashima K. Eosinophilic pustular folliculitis: A proposal of diagnostic and therapeutic algorithms. J Dermatol. 2016 Nov;43(11):1301-6.

5 Nervi SJ, Schwartz RA, Dmochowski M. Eosinophilic pustular folliculitis: a 40 year retrospect. J Am Acad Dermatol. 2006 Aug;55(2):285-9.

6 Mizoguchi S, Setoyama M, Higashi Y, Hozumi H, Kanzaki T. Eosinophilic pustular folliculitis induced by carbamazepine [PMID:9555813]. J Am Acad Dermatol. 1998 Apr;38(4):641-3.

7 Kimura K, Ezoe K, Yokozeki H, Katayama I, Nishioka K. A case of eosinophilic pustular folliculitis (Ofuji's disease) induced by patch and challenge tests with indeloxazine hydrochloride [PMID:8772029]. J Dermatol. 1996 Jul;23(7):479-83.

8 Ooi CG, Walker P, Sidhu SK, Gordon LA, Marshman G. Allopurinol induced generalized eosinophilic pustular folliculitis [PMID:17034470]. Australas J Dermatol. 2006 Nov;47(4):270-3.

9 Fujiyama T, Tokura Y. Clinical and histopathological differential diagnosis of eosinophilic pustular folliculitis. J Dermatol. 2013 Jun;40(6):419-23.

10 Hara D, Kuroda K, Mieno H, Tajima S. Treatment of eosinophilic pustular folliculitis with tacrolimus ointment. J Am Acad Dermatol. 2004 Nov;51(5 Suppl):S143-5.
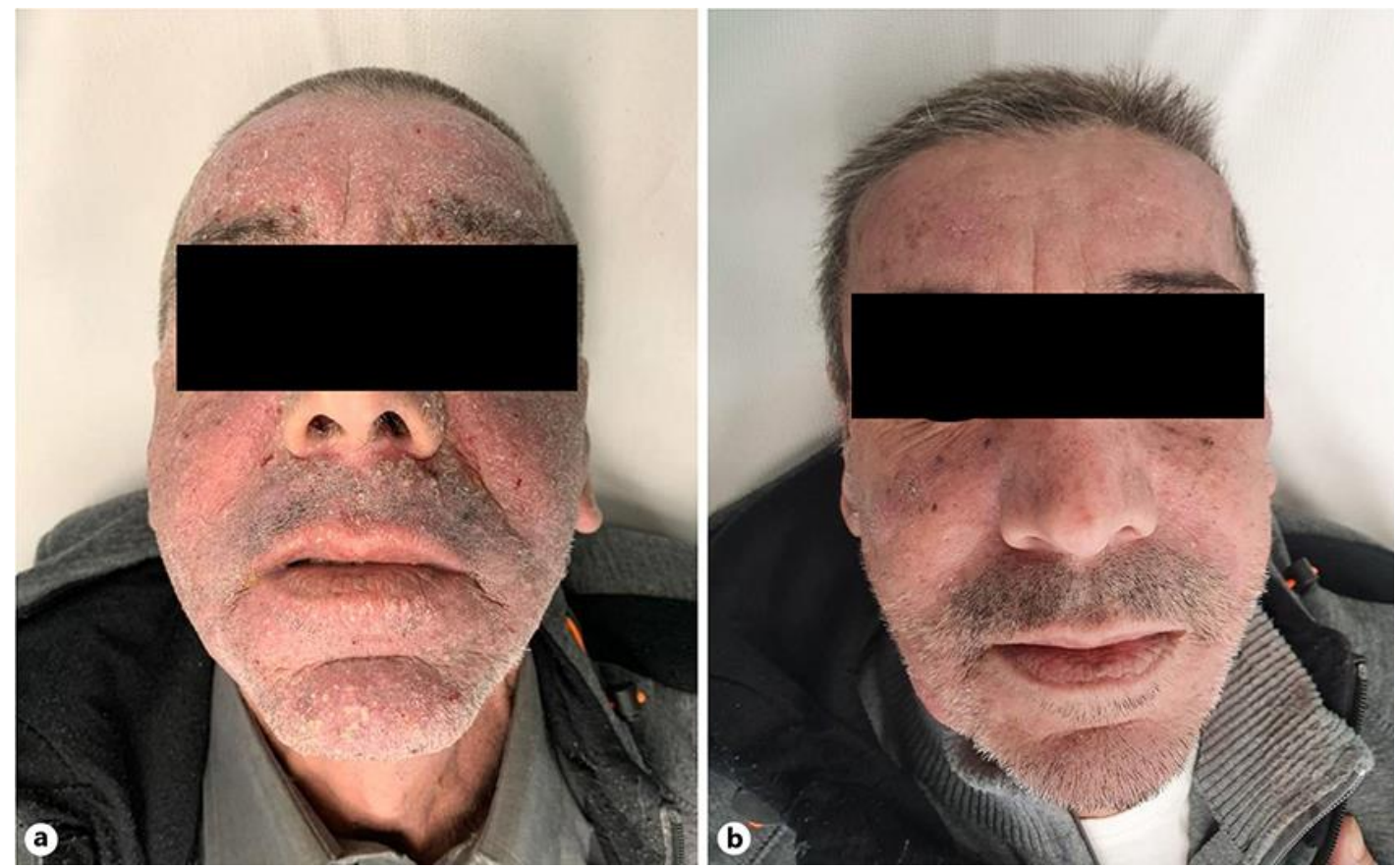

Fig. 1. Patient at baseline (week 0) (a) and after 8 weeks of low dose of oral indomethacin in combination with topical tacrolimus once a day (b). 